\title{
Diabetic Macular Edema - Prognostic Factors
}

\author{
Jay Kumar Chhablani \\ University of California at San Diego, La Jolla, Calif., USA
}

\section{Dear Editor}

I read the article by Roh et al. [1] with interest. This article describes the type of macular edema on optical coherence tomography (OCT) as an important prognostic factor. I would like to add a few comments on the prognostic factors for diabetic macular edema (DME).

Visual acuity in eyes with DME is believed to be mutifactorial including retina thickness [2] and integrity of the retinal architecture, especially that of the photoreceptor layer [3].

Sakamoto et al. [3] reviewed the relationship between the inner segment/outer segment (IS/OS) junction by Stratus OCT after the resolution of DME following pars plana vitrectomy. This study reported that photoreceptor integrity is closely related to final visual acuity [3].

Recently Alasil et al. [4] reported a significant correlation between the integrity of photoreceptor OS thickness and the visual acuity in patients with DME by Stratus OCT. Their findings are consistent with other retinal diseases, including retinitis pigmentosa, birdshot chorioretinopathy and age-related macular degeneration.

\section{References}

1 Roh MI, Kim JH, Kwon OW: Features of optical coherence tomography are predictive of visual outcomes after intravitreal bevacizumab injection for diabetic macular edema. Ophthalmologica 2010;224:374-380.

2 Do DV, Cho M, Nguyen QD, et al: Impact of optical coherence tomography on surgical decision making for epiretinal membranes and vitreomacular traction. Retina 2007;27: 552-556.
Sakamoto A, Nishijima K, Kita M, Oh H, Tsujikawa A, Yoshimura N: Association between foveal photoreceptor status and visual acuity after resolution of diabetic macular edema by pars plana vitrectomy. Graefes Arch Clin Exp Ophthalmol 2009;247:13251330.

4 Alasil T, Keane PA, Updike JF, Dustin L, Ouyang Y, Walsh AC, Sadda SR: Relationship between optical coherence tomography retinal parameters and visual acuity in diabetic macular edema. Ophthalmology 2010, E-pub ahead of print.
Maheshwary et al. [5] evaluated the integrity of the photoreceptor IS/OS junction in relation to the visual acuity using spectral-domain OCT in patients with DME. They reported that disruption of the photoreceptor IS/OS junction is an important predictor of visual acuity among DME patients.

According to the recent literature, photoreceptor integrity is the most important prognostic factor in eyes with DME, yet further evidence is required.

\section{KARGER}

Fax +41613061234 E-Mail karger@karger.ch www.karger.com
Dr. Jay Chhablani

University of California at San Diego

9415 Campus Point Drive, Room 217B

La Jolla, CA 92093 (USA)

E-Mail jay.chhablani@gmail.com
Maheshwary AS, Oster SF, Yuson RM, Cheng L, Mojana F, Freeman WR: The association between percent disruption of the photoreceptor inner segment-outer segment junction and visual acuity in diabetic macular edema. Am J Ophthalmol 2010;150:6367. 